\title{
Alpine, but not montane, seed plants constitute a biogeographically and climatically distinct species pool across the
} Americas.

\author{
Hector Figueroa ${ }^{1}$, Hannah Marx ${ }^{2}$, Maria Beatriz de Souza Cortez ${ }^{3}$, Charles Grady ${ }^{4}$, \\ Nicholas J. Engle-Wrye ${ }^{5}$, Jim Beach ${ }^{6}$, Aimee Stewart ${ }^{6}$, Ryan Folk ${ }^{5}$, Douglas Soltis ${ }^{3}$, \\ Pamela Soltis ${ }^{3}$, and Stephen Smith ${ }^{1}$ \\ ${ }^{1}$ University of Michigan \\ ${ }^{2}$ University of New Mexico Department of Biology \\ ${ }^{3}$ University of Florida \\ ${ }^{4}$ University of Kansas Department of Ecology and Evolutionary Biology \\ ${ }^{5}$ Mississippi State University Department of Biological Sciences \\ ${ }^{6}$ University of Kansas College of Liberal Arts and Sciences
}

April 29, 2021

\begin{abstract}
Aim Higher elevation habitats contribute substantially to global biodiversity. Nevertheless, we know comparatively little about how diversity patterns differ among alpine and montane communities across different mountain ranges. Here, we characterized the realized niche space of American seed plants to ask whether or not montane or alpine community compositions define climatically distinct species pools at this regional scale. Location Americas. Time Period Contemporary. Major taxa studied Seed plants. Methods We assembled a niche model dataset of 72,372 American seed plants based on digitized and georeferenced specimen records. We used this dataset to quantify occupied abiotic niche space with regards to temperature, precipitation, and elevation. This approach further permitted differentiation of higher-elevation specialists (i.e., ranges centered at high elevations) from generalists (i.e., ranges centered at lower elevations but extending into mountain areas). Results Montane communities did not differ from the regional species pool in terms of richness patterns, occupied climatic niche space, or niche breadth. In contrast, alpine communities were characterized by a bimodal latitudinal diversity gradient, drastically reduced climatic niche space, and broader temperature but narrower precipitation niche breadth. Alpine generalists further showed statistically significant differences in temperature, but not precipitation, niche breadth from both alpine specialists and lowland taxa. We also highlight non-alpine species whose climatic niche space otherwise overlapped with that of alpine plants. These species were geographically concentrated in the southern US and Mexico, tended to have a greater fraction of their ranges in frost-exposed mountain foothills, and less of their range in lowland, frost-free, areas, compared to other non-alpine species. Main conclusions These results suggest that ecological and physiological barriers, rather than dispersal limitation might better explain alpine community assembly and that alpine, but not montane, communities form a climatically distinct species pool in the Americas.
\end{abstract}

[BLINDED MAIN TEXT FILE]

TITLE

Alpine, but not montane, seed plants constitute a biogeographically and climatically distinct species pool across the Americas.

\section{RUNNING TITLE}


Contrasting alpine and montane assemblages

\section{ABSTRACT}

Aim

Higher elevation habitats contribute substantially to global biodiversity. Nevertheless, we know comparatively little about how diversity patterns differ among alpine and montane communities across different mountain ranges. Here, we characterized the realized niche space of American seed plants to ask whether or not montane or alpine community compositions define climatically distinct species pools at this regional scale.

Location

Americas.

Time Period

Contemporary.

Major taxa studied

Seed plants.

Methods

We assembled a niche model dataset of 72,372 American seed plants based on digitized and georeferenced specimen records. We used this dataset to quantify occupied abiotic niche space with regards to temperature, precipitation, and elevation. This approach further permitted differentiation of higher-elevation specialists (i.e., ranges centered at high elevations) from generalists (i.e., ranges centered at lower elevations but extending into mountain areas).

Results

Montane communities did not differ from the regional species pool in terms of richness patterns, occupied climatic niche space, or niche breadth. In contrast, alpine communities were characterized by a bimodal latitudinal diversity gradient, drastically reduced climatic niche space, and broader temperature but narrower precipitation niche breadth. Alpine generalists further showed statistically significant differences in temperature, but not precipitation, niche breadth from both alpine specialists and lowland taxa. We also highlight non-alpine species whose climatic niche space otherwise overlapped with that of alpine plants. These species were geographically concentrated in the southern US and Mexico, tended to have a greater fraction of their ranges in frost-exposed mountain foothills, and less of their range in lowland, frost-free, areas, compared to other non-alpine species.

Main conclusions

These results suggest that ecological and physiological barriers, rather than dispersal limitation might better explain alpine community assembly and that alpine, but not montane, communities form a climatically distinct species pool in the Americas.

\section{KEYWORDS}

Alpine flora; American flora; climatic niche; montane flora; regional species pool; species distribution model.

\section{INTRODUCTION}

Elevational and topographic gradients have a substantial influence on biodiversity patterns (Antonelli et al., 2018; Hughes and Atchison, 2015; Rahbek, Borregaard, Colwell, et al., 2019), and high-elevation habitats are among the most diverse in the world (Hughes and Eastwood, 2006; Rahbek, Borregaard, Colwell, et al., 2019; Wen et al., 2014; Xing and Ree, 2017). Mountain range uplift creates substantial topographic heterogeneity, providing a wide variety of microclimatic niche space in which plants can become established 
(Körner, 2003), as well as opportunities for isolation and allopatric speciation, which can promote diversity. Mountain ranges further offer high-elevation corridors for long-range dispersal (Antonelli et al., 2009; Rahbek, Borregaard, Antonelli, et al., 2019), and such routes have potentially exposed plants to low temperatures prior to the onset of Eocene global cooling (Hawkins, Rueda, Rangel, Field, Diniz-Filho, 2014; Qian, 2017). Because tolerance to freezing appears to be a major driver of the biogeographic distributions of plant lineages (Folk, Siniscalchi, Solits, 2020; Hawkins et al., 2014; Qian, 2017; Segovia et al., 2020; Zanne et al., 2014), understanding the relationship between adaptation to high elevation and adaptation to life in the cold could provide crucial insight into the factors shaping modern plant diversity.

In response to the importance of higher elevation habitat in shaping biodiversity patterns, extensive work has been done to delimit different elevational zones across the globe. In particular, Körner, Paulsen, and Spehn (2011) defined seven life thermal belts based on bioclimatic and topographic characteristics: the nival (perpetual snowline), upper alpine, lower alpine (tree line estimate), upper montane, lower montane, remaining mountain area with frost, and remaining mountain area without frost. These thermal zones account for latitudinal differences in the absolute elevation of alpine and montane habitats (Körner et al., 2011) and provide a biologically meaningful and geographically robust assessment of different elevational zones. Further, these elevational belts allow for comparisons of biodiversity patterns across different mountain ranges at large biogeographic scales (Körner et al. 2011).

This classification of the worlds' mountainous habitat types provides an opportunity to differentiate the diversity and biogeographic patterns of alpine and montane communities at the regional scale. Despite the importance of understanding high elevation habitats for biodiversity questions, relatively little is known about what distinguishes montane and alpine floras across mountain ranges (Körner, 1995, 2004). Within the alpine belt, especially, plant species may be subjected to conditions at their physiological limits (Körner, 2003), which might not occur at lower elevations. A key question for montane and alpine biologists is therefore to understand how different processes, such as abiotic filtering, dispersal limitation, and historical contingency (e.g., phylogenetic and biogeographic history), have jointly acted in shaping community assembly in these more remote biodiversity hotspots (Hughes and Eastwood, 2006; Elsen and Tingley, 2015; Flantua, O'Dea, Onstein, Giraldo, Hooghiemstra, 2019), and how these processes differ with elevation. Observed changes in species richness (Guo et al. 2013) and turnover (McFadden et al. 2019; Smithers et al. 2020) across elevational gradients further highlight the potentially complex interplay of factors that define and distinguish alpine from montane communities.

While previous work estimating regional American floral diversity (e.g., Graham 1999, 2010; Ullola Ullola et al. 2017; ter Steege et al. 2020) has yielded invaluable insight into this regional species pool, these estimates generally have not provided an assessment of how much usable data currently exists to define specific aspects of this regional pool's realized niche space. For higher elevation plants, which might be significantly impacted by physiological and ecological limits (Körner, 2003), it could be relevant to know which members of these potential species pools actually do, or could, contribute to montane and alpine communities.

One of the key niche dimensions that determine whether species can establish and survive at different elevations relates to their climatic tolerances. Although numerous climatic variables influence how plants are distributed, temperature and precipitation are often considered among the most important (Clarke and Gaston, 2006; Macarthur, 1972; Whittaker, 1970). Temperature influences processes such as plant growth and metabolic rates (Körner, 2003). Mean annual temperature (MAT), in particular, has shown quantitative correlations with ecologically relevant plant traits (Moles et al., 2014), suggesting it may be an important determinant of ecological strategies. Mean annual precipitation (MAP) is important for its relation to drought tolerance (Craine et al., 2013), and changes in global precipitation and temperature have jointly helped to shape the development of modern American plant biomes, such as the emergence of arid grasslands (Graham, 2011).

In this study, we use a species distribution model (SDM) approach that integrates digitized specimen records and climate data to assemble a large dataset describing the abiotic niches of American seed plants. This dataset provides a detailed look at the contemporary occupied (i.e., realized) niche space of this potential 
regional species pool in order to address questions of higher elevation community assembly. The Americas are particularly well-suited to this analysis because their mountain ranges run north-south in an almost unbroken line from one pole to another, which might have allowed plants to more easily track favorable climate during cycles of glaciation (Bennett, Tzedakis, Willis, 1991; Rahbek, Borregaard, Antonelli, et al., 2019). Here, we model the distributions of 72,372 American seed plants and use these models to characterize their realized abiotic niche space and climatic niche breadth to ask whether or not species occupying montane or alpine habitats constitute measurably distinct biogeographic and/or climatic species pools across the Americas.

\section{METHODS}

Phylogeny, occurrence records, and niche models.

We obtained a dated phylogeny for all seed plants from Smith and Brown (2018; ALLMB phylogeny) and left polytomies unresolved. This phylogeny generated a species list with which to query American specimen records from the Global Biodiversity Information Facility (GBIF) and Integrated Digitized Biocollections (iDigBio). Records were then cleaned and filtered using the BiotaPhy Platform interface (https://biotaphy.github.io), following their accepted best practices.

The full GBIF dataset $\left(\mathrm{N}_{\text {records }}=36,335,199\right)$ is described and accessible at (https://doi.org/10.15468/dl.gtgtt5). Briefly, GBIF records with the following flags were removed: TAXONMATCH_FUZZY, TAXON_MATCH_HIGHER_RANK, TAXON_MATCH_NONE. Further processing was performed after aggregating GBIF and iDigBio records. For iDigBio, data cleaning and filtering produced a dataset of $13,667,523$ records $\left(\mathrm{N}_{\text {initial }}=58,384,427 ; 23.4 \%\right.$ retained $)$. Briefly, initial records were filtered by removing those with any of the following flags: GEOPOINT_DATUM_MISSING, GEOPOINT_BOUNDS, GEOPOINT_DATUM_ERROR, GEOPOINT_SIMILAR_COORD, REV_GEOCODE_MISMATCH,

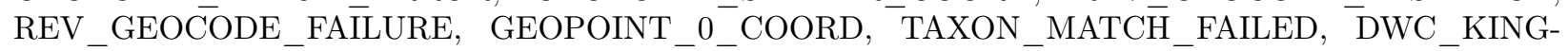
DOM_SUSPECT, DWC_TAXONRANK_INVĀLID, DWC_TAXONRANK_REMOVED. Full details are provided in the Dryad deposit associated with this study (https://doi.org/10.5061/dryad.9cnp5hqgx).

Aggregated GBIF and iDigBio records were then further processed by excluding points with any of the following issues: (1) falling outside the study area (the Americas); (2) less than four decimal point precision ( $\sim 11 \mathrm{~m}$ near the equator); (3) duplicate localities (rarefaction); (4) falling outside polygons describing accepted species' distributions (defined by Plants of the World Online, POWO; Brummitt 2001; www.github.com/tdwg/wgsrpd); (5) species with fewer than twelve records (to build reliable niche models).

Cleaned records were then passed to MaxEnt (version 3.1.4; Phillips, Anderson, Schapire, 2006) along with 2.5' resolution climate data from WorldClim (Fick and Hijmans, 2017) to build species distribution models (SDMs). We chose to perform our analyses using SDMs rather than point occurrence records for two reasons. SDMs offer a probabilistic way of describing expected species' ranges based on the climate from sites where the species has been observed. In this way, SDMs convert presence/ absence data into a continuously valued function, allowing us to ask how distributions are impacted by abiotic factors without having to arbitrarily bin species, as for example, alpine or montane. Second, using SDMs helps overcome some sampling limitations by providing insight into the climatic tolerances of where species might occur, even if they have not been sampled at that precise location (Barthlott et al. 2007; Meyer, Kreft, Guralnik, Jetz, 2015; Brummitt, Araújo, Harris, 2021). Although this could lead to erroneously predicting, for example, that a northern boreal species should occur at extreme southern latitudes, we overcome this obstacle by masking the SDMs with polygons provided by POWO that define geographically broad areas where each species occurs based on expert assessments. This approach thus constrained SDMs by both known areas of occurrence and climatic tolerances.

Characterizing abiotic niches.

We used the SDMs described above to characterize abiotic niches of each species with respect to mean annual temperature (MAT), precipitation (MAP), and elevation, by parsing the fraction of the SDM attributable to an increment of that abiotic variable. Increments were $1^{\circ} \mathrm{C}$ for MAT and $250 \mathrm{~mm}$ for MAP. For elevation, we used the seven bioclimatic zones defined by the Global Mountain Biodiversity Assessment (GMBA; Körner 
et al., 2011, 2017; Körner and Paulsen, 2004; 2.5' resolution). These zones integrate temperature, growing season length, and topographic information to provide a robust and biogeographically relevant assessment of the extent and type of montane and alpine habitat across the globe. They further permit an assignment of species distributions along elevational gradients despite latitudinal differences in what constitutes montane and alpine areas. Nevertheless, these bioclimatic categories are fundamentally defined by isothermal zones, and are not therefore an independent axis from MAT (Körner et al., 2011). However, our goal was not to define independent niche axes per se, but rather to characterize abiotic niches in a biologically meaningful way. The GMBA-defined zones provide the current best estimate of a biogeographically relevant classification of mountain systems (Körner et al., 2017). The seven GMBA bioclimatic zones used to define species' elevation niche were: 1-nival; 2-upper alpine; 3-lower alpine; 4-upper montane; 5-lower montane; 6-mountain slope with frost; 7-mountain slope without frost or lowland. We chose to combine GMBA zone 7 with lowland areas for our study; thus, our assessment of lowland distributions was fundamentally linked with exposure to freezing temperatures.

This method yielded three vectors that jointly quantified the distribution of niche space potentially occupied by each species (e.g., $10 \%$ probability a species will be present at a site with MAP of $500 \mathrm{~mm}$ ). Figure 1 plots some representative examples and provides a conceptual illustration of our characterization of abiotic niches and dataset assembly. In this way, we avoided having to arbitrarily bin species into habitat categories, such as alpine or lowland, and instead could assess niches as continuously valued distributions of occupied niche space. Parsing of SDMs was performed using custom Python scripts (available at: https://doi.org/10.5061/dryad.9cnp5hqgx).

To visualize the climatic (temp. or prec.) niche space occupied by species in our dataset, we integrated each climate vector to obtain a weighted average value that characterized the center of each species' range (i.e., climatic conditions in locations where the SDM score was higher were given proportionally higher weight). The resulting values thus described the climatic conditions in regions of that species' range where the species was expected to be more abundant, as opposed to characterizing the most extreme climatic values where a species is found. This realized climatic niche space was then contrasted among species occupying different elevations.

The elevation niche vector was used to assign species into categories such as 'alpine' or 'specialist'. Though such distinctions can be arbitrary, when used to express where the center of a species' range is expected to occur, they can be used to provide valuable biological insight (Körner, 2003). In this study, the 'specialist' category indicated the likely central habitat of a species' range, and so we required specialists to have at least $60 \%$ of their SDM in that habitat type. For elevational categories, such as alpine or montane, we required a species to have at least $5 \%$ of their total SDM in that category, regardless of whether such habitat was contiguous or not. Thus, an alpine specialist in this study would have at least $60 \%$ of its SDM in alpine regions, whereas an alpine generalist could have anywhere from $5 \%$ to $59 \%$ of its modelled range in the alpine belt (Supplemental Fig. S1).

Quantifying climatic niche breadth.

We quantified the temperature and precipitation niche breadth of each species as follows, using custom scripts in the $\mathrm{R}$ statistical computing environment ( $\mathrm{R}$ Core Team, 2020) and the resulting climatic niche breadth distributions were contrasted among species occupying different elevations. Having parsed the SDMs among small increments of each climatic variable, we interpreted these climatic vectors as representing states a species could occupy within its range. We used Levins' (1968) niche breadth index to quantify SDM uniformity across the full suite of possible climatic states for either MAT or MAP using: 


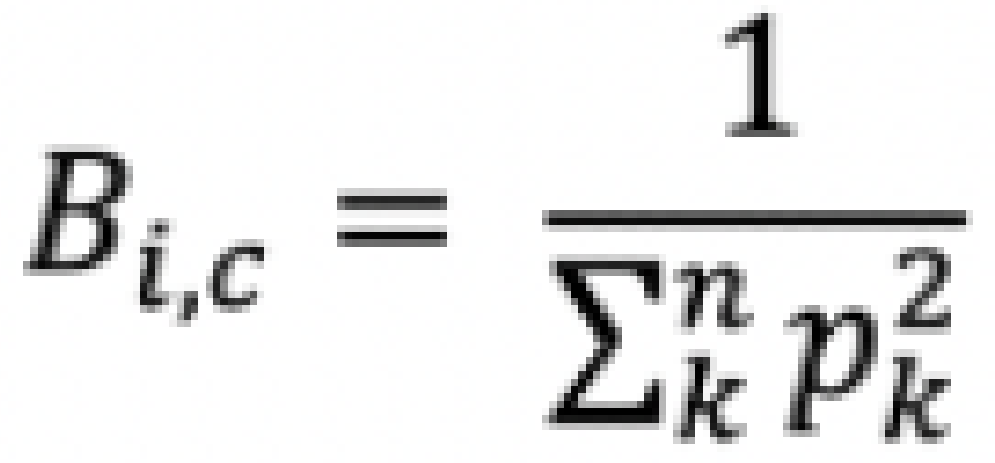

Where $B_{i, c}$ is the niche breadth of species $i$ with respect to climate variable $c$, and $p$ is the proportion of that species' SDM found in state $k$ of the climatic variable (e.g., within each $1^{\circ} \mathrm{C}$ increment of temperature or $250 \mathrm{~mm}$ increment of precipitation). To facilitate comparison across species and different niche variables, we calculated a standardized niche breadth, $\hat{B}_{i, c}$, bound between zero and one, by dividing niche breadth by the number of possible states $(n)$, corrected for the finite number of states:
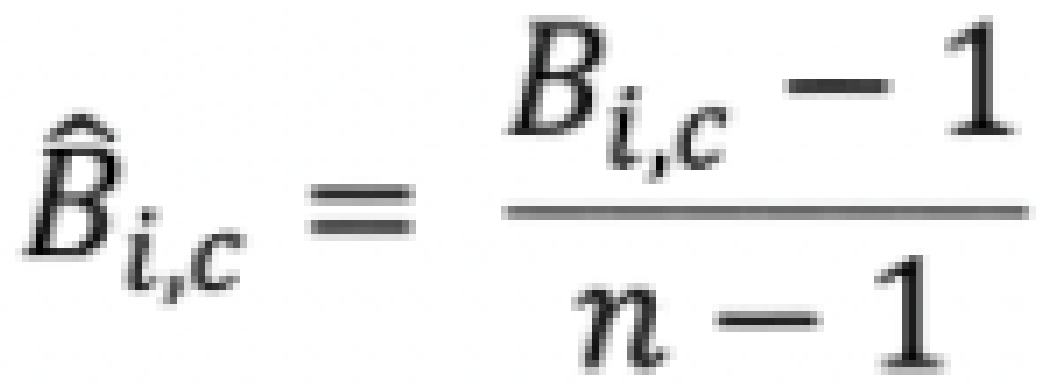

Species richness calculations.

GMBA provides 2.5' resolution shapefiles delimiting each mountain (e.g., Abajo Peak) and mountain range (e.g., Appalachia or the Andes) in the Americas. To assess diversity metrics, such as species richness, we first parsed the Americas shapefiles into half-degree grid cells ('sites') and tabulated which species were predicted to be present within each site (presence required at least a $5 \%$ chance of finding the species within at least $25 \%$ of the area covered by the grid cell). Total site richness was obtained by summing the number of species predicted for each site (Fig. 2). Expected species lists resulting from this method, cross-referenced by country, were deposited with Dryad (https://doi.org/10.5061/dryad.9cnp5hqgx).

\section{RESULTS}

Dataset construction and description of abiotic niches .

Our data cleaning and filtering methods produced a dataset of 50,002,722 georeferenced occurrence records spanning 72,372 seed plant species, of which 68,241 could be matched back to our phylogeny (totaling 5397 genera or $\sim 18 \%$ of total estimated seed plant lineages; Stevens, 2001; Smith and Brown, 2018), with broad 
geographic coverage of the Americas, including all mountains (Fig. 2a). There were notable geographic areas of poor sampling, including the Amazon basin and extreme southern and northern latitudes. From these occurrence records, we built species distribution models (SDMs) to characterize mean annual temperature (MAT), precipitation (MAP), and elevation niches. Importantly, these niches were characterized as continuously valued distributions and not as scalar values. Figure 1 illustrates an example of this niche characterization for a single species, Astragalus alpinus L. ('alpine milkvetch'), whose composite niche is centered within montane habitat (i.e., $>60 \%$ of the modelled range falls within montane area) and is bounded between approximately $-17^{\circ}$ and $+10^{\circ} \mathrm{C}$, and generally below $1000 \mathrm{~mm}$ of precipitation. This type of niche characterization allowed us to define the fraction of each species' range occurring within different combinations of abiotic conditions.

Species richness in different elevational categories .

Comparing species richness across different elevational belts revealed contrasting patterns of diversity for species occupying lowland $\left(\mathrm{N}_{\text {lowland }}=36,420\right)$, montane $\left(\mathrm{N}_{\text {montane }}=33,015\right)$, and alpine $\left(\mathrm{N}_{\text {alpine }}=2937\right)$ habitats. Across all seed plants, we observed a traditional latitudinal diversity gradient, with richness peaking near the equator (Fig. 2a). This pattern was nearly identical when considering solely montane communities (i.e., species with at least $5 \%$ of their range in the montane belt; Fig. 2b). For alpine communities, however, species richness was latitudinally bimodal, peaking in both the western North American cordillera and the central Andes (Fig. 2c).

Climatic niche space of lowland, montane, and alpine communities .

The temperature and precipitation niche space occupied across all species in our dataset (Fig. 3a) generally mirrored that defining the climate space of the regional biomes, indicating that our modelled distributions recapitulated the likely climatic niche space of the Americas overall. Lowland and montane species occupied similar regions of climatic space as seed plants generally (Fig. 3a-c), though lowland taxa exhibited a greater density at higher precipitation values, and very few lowland species had ranges centered in habitats with mean annual temperature below freezing (though certainly many had ranges extending into these regions). Indeed, montane species seemed to occupy a greater total niche volume than lowland taxa here. In contrast, the climatic niche space of alpine species (Fig. 3d) was drastically reduced and shifted toward colder and drier habitats. Alpine communities were more uniform in their occupied precipitation niche space, but somewhat bimodal in the occupied temperature space, with a small, dense cluster of species having ranges centered on areas with $-10^{\circ} \mathrm{C}$ MAT.

Climatic niche breadth across elevational gradients .

The distributions of average, standardized, niche breadths $(B)$ across all American seed plants (Fig. 4a) were generally narrow $\left(B_{T E M P}=0.130 \pm 0.08 ; B_{P R E C}=0.099 \pm 0.08\right)$, but with long tails, indicating much greater niche breadth for only some species as relatively few species had both large $B_{T E M P}$ and $B_{P R E C}$. The niche breadths of montane species were generally similar to those of seed plants overall (Fig. 4c), though montane species had increased $B_{T E M P}$. Alpine species, however, occupied a reduced total niche breadth space, characterized by broad $B_{T E M P}$ and narrow $B_{P R E C}$ (Fig. $4 \mathrm{~d}$ ).

Generalist species within each elevational category had maximal $B_{T E M P}$ (Fig. 5, top row), with an abrupt increase in $B_{T E M P}$ observed for alpine generalists. $B_{P R E C}$, in contrast, was generally narrow regardless of elevation or specialization (Fig. 5, bottom row). Across our dataset, genera with alpine specialists had a greater fraction of both alpine generalists and montanespecialists (Supplemental Fig. S2; Figueroa et al., pers. comm. ). Spatial variation in community-averaged niche breadth (Supplemental Fig. S3) indicated higher $B_{T E M P}$ at greater absolute latitudes (particularly in the Northern Hemisphere) and in mountains compared to surrounding lowlands. In contrast, $B_{P R E C}$ was largest near the equator, regardless of elevation. Most mountains showed lower $B_{P R E C}$ than nearby lowlands, exceptions being some Central American mountains, the Northern Andes, and the southernmost Andes. As a result, the Northern Andes are notable here for having greater community-averaged niche breadth for both temperature and precipitation. 
Climatically Similar Non-Alpine (CSNA) species .

Climatically Similar Non-Alpine (CSNA) species, defined here as non-alpine species whose ranges otherwise overlapped with the climatic conditions of alpine taxa (Fig. 2d and 6) tended to cluster geographically in the southwestern US and Mexico (Fig. 2d, 6e), and therefore also departed from a traditional latitudinal diversity gradient as their greatest richness occurred at $\sim 20^{\circ} \mathrm{N}$. Although regions with higher CSNA richness harbored the lowest alpine diversity (Fig. 2d), richness between these groups at these areas was strongly and positively correlated $\left(\mathrm{R}^{2}=0.68, \mathrm{p}<0.001\right.$; Fig. 6e). CSNA species ranges (Fig. 6d) contained a significantly greater fraction of frost-exposed mountain foothills $(\mathrm{p}<0.01)$ and lower fraction of frost-free lowland $(\mathrm{p}<0.01)$, compared to other non-alpine species. To a lesser extent, they also had a greater proportion of their ranges in the lower montane belt than other non-alpine taxa. At the phylogenetic scale of the American seed plant flora, there was no clear separation between alpine and CSNA species (Fig. 6a). However, there were substantial differences in the taxonomic composition of these groups at finer phylogenetic scales (Table 1 and online supplement), with several orders containing CSNA but not alpine species, and only $\sim 28 \%$ overlap in genera between CSNA and alpines $\left(\mathrm{N}_{\text {alpine_genera }}=717 ; \mathrm{N}_{\mathrm{CSNA} \_ \text {genera }}=1421 ; \mathrm{N}_{\text {shared_genera }}=395\right)$.

\section{DISCUSSION}

\section{Dataset considerations.}

Our distribution model (SDM) approach, rather than the exclusive use of point occurrence records, helped to overcome issues of incomplete sampling (Barthlott et al., 2007; Meyer et al., 2015; Brummitt et al., 2021), and provided broader, macroecological insight into how species in lowland, montane, and alpine regions differ in terms of their occupied climatic niche space. In general, while the quality and extent of species sampling (Fig. 2) was good, we were unable to generate SDMs for every American seed plant. With 68,241 species matched to our phylogeny, we covered only $\sim 18 \%$ of estimated global seed plant lineages (Stevens, 2001), and less than $\sim 48 \%$ of the total estimated American floral diversity (Ullola Ullola et al., 2017). Further, the threshold minimum of twelve records to build reliable SDMs certainly excluded numerous range-limited endemics, which is likely to disproportionately impact representation of Andean alpine lineages, where the degree of alpine endemism is substantial (Hughes and Eastwood, 2006). With these limitations in mind, we have attempted to draw broad, macroecological conclusions that are unlikely to be significantly impacted by loss of models for range-limited endemics. Nevertheless, species excluded as a result of the conservative nature of our data cleaning protocol highlight the need for increased sampling of range-limited endemics to enhance the broader understanding of how such species impact macroecological patterns and conclusions.

Further, although we have grouped communities by elevational categories, important differences between Northern and Southern Hemisphere alpine habitats, such as the degree of seasonality, growing season length, and extent and duration of snow cover, should be taken into account when forming conclusions from this macroecological dataset. For instance, in our dataset, we did not find a correlation between species richness and elevation in alpine-only communities (data not shown), and it may be that there are many avenues by which a region or local community can achieve a high level of biodiversity (Hughes, 2017). Future studies should investigate how more local-scale processes might be influencing the observed macroecological patterns we find here.

\section{Contrasts across elevation belts and specialization .}

A species pool defines a collection of organisms in the region. However, another aspect of a species pool is the subset of that potential community species pool that is able to colonize and survive in the local setting (Emerson and Gillespie, 2008). Although myriad factors determine which plant species are able to persist in montane and alpine regions (Körner, 2003), here we investigated a portion of the macroscale abiotic niche space occupied by American seed plants to provide insight into how factors such as temperature and precipitation might impact species distributions (Moles et al., 2014). Compared to non-alpine species, those inhabiting alpine habitats, regardless of whether such species had ranges centered in the alpine belt or elsewhere, showed unique richness patterns (Fig. 2c), occupied a drastically reduced climatic niche space (Fig. 3d), and showed broad temperature but narrow precipitation niche breadth (Fig. 4d). Elsewhere, we 
have also shown that these alpine species showed distinct patterns of phylogenetic diversity (Figueroa et al., pers. comm. ). In contrast, species in the montane belt were relatively similar to both the species pool overall and lowland taxa in their observed richness patterns, occupied niche space, niche breadth (Fig. 2-4), and phylogenetic diversity (Figueroa et al., pers. comm. ). These findings underscore the unique confluence of factors that define plant diversity at the extreme elevational limits of the alpine belt (Körner, 2003) and reiterate the complexity of defining an appropriate regional pool for such an ecosystem.

These results showed a notable separation between the occupied climatic niche space of alpine and non-alpine communities. That there was not a similarly clear separation between montane and lowland communities raises the question of what distinguishes montane communities from adjacent assemblies. One distinguishing factor is certainly their greater plant diversity (Grytnes and Vetaas, 2002; Grytnes, 2003; Cardelús, Colwell, Watkins, 2006). Additionally, montane environments at tropical latitudes display greater phylogenetic affinity with temperate lowlands (González-Caro et al., 2020), suggesting cooler-climate corridors have been used to track amenable climate, allowing montane species to colonize lowlands (Donoghue, 2008).

In this study, we found that niche breadth tended to be maximal for montane generalists (Fig. 6), indicating the possibility of montane regions representing a transitional zone, in which the greatest variety of forms from other elevations could coexist. This is conceptually analogous to the often-observed mid-elevation peak in species richness (Grytnes and Vetaas, 2002; Grytnes, 2003; González-Caro et al., 2020). However, our results differ subtly but importantly from such observations in two ways. First, our elevational categories are based on habitat type (Körner et al., 2011) and not absolute elevation per se. Second, we demonstrate that montane communities occupy a broad climatic niche space and have greater niche breadth than alpine communities. These niche characteristics are not identical to species richness, though they could be influenced by it.

Concomitantly, montane communities could also be distinguished from alpine ones by factors other than those examined here, such as soil and mineral conditions (Egli and Poulenard, 2016), pest and pathogen distributions (Rasmann et al., 2014), and/or the distributions of dispersal agents. Additionally, although at the regional scale montane communities overlapped in climatic niche space with lowland sites, this did not mean montane community composition matched that of lowland areas occurring at the same latitude. At the same time, the greatly reduced alpine diversity in Central America might suggest a greater role for dispersal limitation for alpine lineages compared to montane ones (Figueroa et al., pers. comm. ), which could also contribute to explaining differences in distributional patterns between alpine and montane communities in this region.

In addition to contrasting the climatic niches of species occurring within different elevation belts, our SDM approach allowed us to incorporate some biological variation in the climate species experience across their ranges, while also quantifying the fraction of each species' range occurring in different climatic conditions. We could thus distinguish between species with ranges centered in alpine or montane habitat (i.e., highelevation 'specialists') from those whose ranges extended into higher elevations but were centered in different habitats (i.e., high-elevation 'generalists'). These distinctions influence what constitutes an alpine species (Körner, 2003) and could reflect different adaptive responses and tolerances. Under our classifications, we found that alpine generalists differed significantly in $B_{T E M P}$ from both alpine specialists and non-alpine species (regardless of elevation).

These results might suggest different strategies are needed by alpine generalists and specialists with respect to temperature responses, as the generalist species may encounter a wider range of temperatures than the specialists. At the same time, in this dataset, genera with alpinespecialists had a greater fraction of both alpinegeneralists and montane specialists (Supplemental Fig. S2; Figueroa et al., pers. comm.). This could indicate that alpine specialists derive mainly from alpine generalists and montane specialists (i.e., diversification has occurred as species encountered novel, higher-elevation habitat), consistent with a "montane speciation model' (sensu Roy, 1997; but see Dagallier et al., 2020). It could also indicate that alpine specialists tend to arise within lineages having greater evolutionary potential to adapt to high-elevation conditions, even if the strategies involved differ among these lineages (Folk et al., 2020; Martínez-Padilla, Estrada, Early, 
García-Gonzalez, 2017). However, we also acknowledge that our climate analyses incorporated only macroscopic conditions and did not address ways in which species at high elevations find and create microclimatic conditions to enhance survival (Körner, 2003; Ohler, Lechleitner, Junker, 2020).

Climatically-Similar Non-Alpine (CSNA) species.

Among non-alpine species, the subset whose ranges occupied similar temperature, precipitation, and nichebreadth space as those found in the alpine belt (CSNA species, as defined above) provided a possible first approximation of which non-alpine American seed plant species might otherwise be able to inhabit the alpine belt and help address a key question of whether abiotic factors or historical processes (e.g., phylogenetic and biogeographic history) plays a larger role in alpine community assembly (e.g., Hughes and Eastwood, 2006).

CSNA species were distributed broadly across the Americas (Fig. 2d), but concentrated in the southern US and in Mexico, and tended to have ranges with a greater proportion in frost-exposed foothills and lower montane habitat (Fig. 6d). This might suggest that ecological and physiological factors, rather than general dispersal limitation, constrains the ability of these species to enter the alpine belt. It is particularly interesting to note that CSNA species had their greatest richness in the same areas where alpine species richness was lowest, namely in and around Mexican mountains (Fig. 2c,d, 6e). This might suggest a role for ecological factors, such as competitive dynamics, in separating the distributions of these species along elevation, however finer scale studies are needed to specifically address such hypotheses since macro-scale analyses capture mostly biogeographical processes (Webb, Ackerly, McPeek, Donoghue, 2002).

Apart from ecological interactions, physiological limitations could also contribute to why these CSNA species have not entered the alpine belt. Alpine habitats are often at the physiological limits of what plants can tolerate (Körner, 2003). This strong abiotic filter might impose significant challenges and therefore prevent a larger number of lineages from entering the alpine environment. Only $\sim 28 \%$ of CSNA genera overlapped with those of actual alpine species, and ten taxonomic orders differed between these groups (Table 1). Such disparity in the taxonomic composition of these groups might be consistent with strong abiotic filtering that only approximately $\frac{1}{4}$ of CSNA genera have been able to overcome at this time.

Although the 'competition-filtering' dichotomy presents a reasonable framework with which to form testable hypotheses concerning the separation of alpine and CSNA species, these are not the only possible explanations for why certain species have not entered the alpine belt. As noted above for montane communities, soil conditions, and pathogen or dispersal-agent distributions, as well as changes to growth form (Sklenár̆, Kučerová, Macková, Romoleroux, 2016) are all additional, non-mutually exclusive factors that could differ between these groups and their ranges. Another interesting, but seemingly untested, possibility is that the American alpine belt is at its current carrying capacity.

\section{Conclusions .}

Higher elevations provide substantial topographic and climatic heterogeneity that can help promote and maintain biodiversity. By assembling a large macroecological dataset modelling the ranges of over 70,000 American seed plants, we were able to provide a detailed investigation of the realized abiotic niche space of this species pool and characterize climatic niches for these species in a biologically meaningful manner. Our approach also allowed us to separate distinct and biologically relevant groups, such as alpine specialists from generalists, or climatically similar species that seem otherwise capable of inhabiting the alpine belt. We found that alpine, but not montane, communities formed a climatically distinct species pool across the Americas. These results present a detailed assessment of the current state of knowledge on the distribution of American seed plants, which would be especially enhanced by greater sampling of range-limited alpine endemics, and underscores the importance of understanding regional-scale diversity patterns in relation to climate and elevation.

\section{REFERENCES}

1. Antonelli, A., Kissling, W. D., Flantua, S. G. A., Bermúdez, M. A., Mulch, A., Muellner-Riehl, A. N., Kreft, H., Linder, H. P., Badgley, C., Fjeldså, J., Fritz, S. A., Rahbek, C., Herman, F., Hooghiemstra, H., 
and Hoorn, C. (2018). Geological and climatic influences on mountain biodiversity. Nature Geoscience, 11(10), 718-725. https://doi.org/10.1038/s41561-018-0236-z

2. Antonelli, A., Nylander, J. A. A., Persson, C., and Sanmartín, I. (2009). Tracing the impact of the Andean uplift on Neotropical plant evolution. Proceedings of the National Academy of Sciences,106 (24), 9749-9754. https://doi.org/10.1073/pnas.0811421106

3. Barthlott, W., Hostert, A., Kier, G., Küper, W., Kreft, H., Mutke, J., Rafiqpoor, M. D., and Sommer, J. H. (2007). Geographic Patterns of Vascular Plant Diversity at Continental to Global Scales (Geographische Muster der Gefäßpflanzenvielfalt im kontinentalen und globalen Maßstab). Erdkunde, 61(4), 305-315.

4. Bennett, K. D., Tzedakis, P. C., and Willis, K. J. (1991). Quaternary Refugia of North European Trees. Journal of Biogeography,18(1), 103-115. https://doi.org/10.2307/2845248

5. Brummitt, N., Araújo, A. C., and Harris, T. (2021). Areas of plant diversity-What do we know? PLANTS, PEOPLE, PLANET,3(1), 33-44. https://doi.org/10.1002/ppp3.10110

6. Brummitt, R. K. (2001). World geographical scheme for recording plant distributions(ed. 2). Hunt Inst. for Botanical Documentation.

7. Cardelús, C.L., Colwell, R.K., and Watkins, J.E. (2006) Vascular epiphyte distribution patterns: explaining the mid-elevation richness peak. J. Ecol., $94(1), 144-156$. http://doi.wiley.com/10.1111/j.13652745.2005.01052.x

8. Clarke, A., and Gaston, K. J. (2006). Climate, energy and diversity.Proceedings of the Royal Society B: Biological Sciences,273(1599), 2257-2266. https://doi.org/10.1098/rspb.2006.3545

9. Craine, J. M., Ocheltree, T. W., Nippert, J. B., Towne, E. G., Skibbe, A. M., Kembel, S. W., and Fargione, J. E. (2013). Global diversity of drought tolerance and grassland climate-change resilience. Nature Climate Change, 3(1), 63-67. https://doi.org/10.1038/nclimate1634

10. Dagallier, L.-P. M. J., Janssens, S. B., Dauby, G., Blach-Overgaard, A., Mackinder, B. A., Droissart, V., Svenning, J.-C., Sosef, M. S. M., Stevart, T., Harris, D. J., Sonke, B., Wieringa, J. J., Hardy, O. J., and Couvreur, T. L. P. (2020). Cradles and museums of generic plant diversity across tropical Africa. New Phytologist,225 (5), 2196-2213. https://doi.org/10.1111/nph.16293

11. Donoghue, M.J. (2008) A phylogenetic perspective on the distribution of plant diversity. PNAS, 105, 11549-11555.

12. Egli, M., and Poulenard, J. (2016). Soils of Mountainous Landscapes. In D. Richardson, N. Castree, M. F. Goodchild, A. Kobayashi, W. Liu, and R. A. Marston (Eds.), International Encyclopedia of Geography: People, the Earth, Environment and Technology(pp. 1-10). John Wiley and Sons, Ltd. https://doi.org/10.1002/9781118786352.wbieg0197

13. Elsen, P. R., and Tingley, M. W. (2015). Global mountain topography and the fate of montane species under climate change. Nature Climate Change, 5(8), 772-776. https://doi.org/10.1038/nclimate2656

14. Emerson, B. C., and Gillespie, R. G. (2008). Phylogenetic analysis of community assembly and structure over space and time. Trends in Ecology and Evolution, 23(11), 619-630. https://doi.org/10.1016/j.tree.2008.07.005

15. Fick, S. E., and Hijmans, R. J. (2017). WorldClim 2: New 1-km spatial resolution climate surfaces for global land areas. International Journal of Climatology, 37(12), 4302-4315. https://doi.org/10.1002/joc.5086

16. Flantua, S. G. A., O'Dea, A., Onstein, R. E., Giraldo, C., and Hooghiemstra, H. (2019). The flickering connectivity system of the north Andean paramos. Journal of Biogeography,46(8), 1808-1825. https://doi.org/10.1111/jbi.13607

17. Folk, R. A., Siniscalchi, C. M., and Soltis, D. E. (2020). Angiosperms at the edge: Extremity, diversity, and phylogeny. Plant, Cell and Environment, 43(12), 2871-2893. https://doi.org/10.1111/pce.13887

18. Graham, A. (1999). Late Cretaceous and Cenozoic History of North American Vegetation.Oxford University Press.

19. Graham, A. (2010). Late Cretaceous and Cenozoic History of Latin American Vegetation and Terrestrial Environments. Missouri Botanical Garden Press.

20. Graham, A. (2011). The age and diversification of terrestrial New World ecosystems 
through Cretaceous and Cenozoic time. American Journal of Botany, 98(3), 336-351. https://doi.org/10.3732/ajb.1000353

21. Grytnes, J.A. (2003) Species-richness patterns of vascular plants along seven altitudinal transects in Norway. Ecography,26 (3), 291-300. http://doi.wiley.com/10.1034/j.1600-0587.2003.03358.x

22. Grytnes J.A. and Vetaass, O.R. (2002) Species richness and altitude: a comparison between null models and interpolated plant species richness along the Himalayan altitudinal gradient, Nepal. Am. Nat., 159(3), 294-304.

23. Guo, Q., Kelt, D. A., Sun, Z., Liu, H., Hu, L., Ren, H., and Wen, J. (2013). Global variation in elevational diversity patterns.Scientific Reports, 3(1), 3007. https://doi.org/10.1038/srep03007

24. Hawkins, B. A., Rueda, M., Rangel, T. F., Field, R., and Diniz-Filho, J. A. F. (2014). Community phylogenetics at the biogeographical scale: Cold tolerance, niche conservatism and the structure of North American forests. Journal of Biogeography, 41(1), 23-38. https://doi.org/10.1111/jbi.12171

25. Hughes, C. E. (2017). Are there many different routes to becoming a global biodiversity hotspot? Proceedings of the National Academy of Sciences , 114 (17), 4275-4277. https://doi.org/10.1073/pnas.1703798114

26. Hughes, C., and Atchison, G. W. (2015). The ubiquity of alpine plant radiations: From the Andes to the Hengduan Mountains. New Phytologist, 207(2), 275-282. https://doi.org/10.1111/nph.13230

27. Hughes, C., and Eastwood, R. (2006). Island radiation on a continental scale: Exceptional rates of plant diversification after uplift of the Andes. Proceedings of the National Academy of Sciences,103(27), 10334-10339. https://doi.org/10.1073/pnas.0601928103

28. Korner, C. (1995). Alpine Plant Diversity: A Global Survey and Functional Interpretations. In F. S. Chapin and C. Korner (Eds.),Arctic and Alpine Biodiversity: Patterns, Causes and Ecosystem Consequences(pp. 45-62). Springer. https://doi.org/10.1007/978-3-642-78966-3_4

29. Korner, C. (2003). Alpine plant life: Functional plant ecology of high mountain ecosystems.(2nd ed.). Springer.

30. Korner, C. (2004). Mountain Biodiversity, Its Causes and Function.AMBIO: A Journal of the Human Environment, 33(sp13), 11-17. https://doi.org/10.1007/0044-7447-33.sp13.11

31. Korner, C., Jetz, W., Paulsen, J., Payne, D., Rudmann-Maurer, K., and M. Spehn, E. (2017). A global inventory of mountains for bio-geographical applications. Alpine Botany, 127(1), 1-15. https://doi.org/10.1007/s00035-016-0182-6

32. Korner, C., and Paulsen, J. (2004). A world-wide study of high altitude treeline temperatures. Journal of Biogeography,31(5), 713-732. https://doi.org/10.1111/j.1365-2699.2003.01043.x

33. Korner, C., Paulsen, J., and Spehn, E. M. (2011). A definition of mountains and their bioclimatic belts for global comparisons of biodiversity data. Alpine Botany, 121(2), 73-78. https://doi.org/10.1007/s00035-011-0094-4

34. Levins, R. (1968). Evolution in changing environments.Princeton University Press.

35. MacArthur, R. H. (1972). Geographical ecology: Patterns in the distribution of species.Princeton University Press.

36. Martinez-Padilla, J., Estrada, A., Early, R., and Garcia-Gonzalez, F. (2017). Evolvability meets biogeography: Evolutionary potential decreases at high and low environmental favourability.Proceedings of the Royal Society B: Biological Sciences,284(1856), 20170516. https://doi.org/10.1098/rspb.2017.0516

37. McFadden, I. R., Sandel, B., Tsirogiannis, C., Morueta-Holme, N., Svenning, J.-C., Enquist, B. J., and Kraft, N. J. B. (2019). Temperature shapes opposing latitudinal gradients of plant taxonomic and phylogenetic $\beta$ diversity. Ecology Letters, 22(7), 1126-1135. https://doi.org/10.1111/ele.13269

38. Meyer, C., Kreft, H., Guralnick, R., and Jetz, W. (2015). Global priorities for an effective information basis of biodiversity distributions. Nature Communications, 6(1), 8221. https://doi.org/10.1038/ncomms9221

39. Moles, A. T., Perkins, S. E., Laffan, S. W., Flores-Moreno, H., Awasthy, M., Tindall, M. L., Sack, L., Pitman, A., Kattge, J., Aarssen, L. W., Anand, M., Bahn, M., Blonder, B., Cavender-Bares, J., Cornelissen, J. H. C., Cornwell, W. K., Díaz, S., Dickie, J. B., Freschet, G. T., ... Bonser, S. P. (2014). Which is a better predictor of plant traits: Temperature or precipitation? Journal of Vegetation 
Science,25(5), 1167-1180. https://doi.org/10.1111/jvs.12190

40. Ohler, L.-M., Lechleitner, M., and Junker, R. R. (2020). Microclimatic effects on alpine plant communities and flower-visitor interactions.Scientific Reports , 10 (1), 1366. https://doi.org/10.1038/s41598020-58388-7

41. Phillips, S. J., Anderson, R. P., and Schapire, R. E. (2006). Maximum entropy modeling of species geographic distributions. Ecological Modelling, 190(3), 231-259. https://doi.org/10.1016/j.ecolmodel.2005.03.026

42. Qian, H. (2017). Relationship between clade age and temperature for angiosperm tree species in forest communities along an elevational gradient in tropical Asia. Journal of Plant Ecology,10(4), 618-625. https://doi.org/10.1093/jpe/rtw074

43. R Development Core Team. (2020). R: a language and environment for statistical computing.R Foundation for Statistical Computing.

44. Rahbek, C., Borregaard, M. K., Antonelli, A., Colwell, R. K., Holt, B. G., Nogues-Bravo, D., Rasmussen, C. M. Ø., Richardson, K., Rosing, M. T., Whittaker, R. J., and Fjeldså, J. (2019). Building mountain biodiversity: Geological and evolutionary processes.Science,365(6458), 1114-1119. https://doi.org/10.1126/science.aax0151

45. Rahbek, C., Borregaard, M. K., Colwell, R. K., Dalsgaard, B., Holt, B. G., Morueta-Holme, N., NoguesBravo, D., Whittaker, R. J., and Fjeldså, J. (2019). Humboldt's enigma: What causes global patterns of mountain biodiversity? Science, 365(6458), 1108-1113. https://doi.org/10.1126/science.aax0149

46. Rasmann, S., Pellissier, L., Defossez, E., Jactel, H., and Kunstler, G. (2014). Climate-driven change in plant-insect interactions along elevation gradients. Functional Ecology,28(1), 46-54. https://doi.org/10.1111/1365-2435.12135

47. Roy, M. S. (1997). Recent diversification in African greenbuls (Pycnonotidae: Andropadus) supports a montane speciation model.Proceedings of the Royal Society of London. Series B: Biological Sciences, 264 (1386), 1337-1344. https://doi.org/10.1098/rspb.1997.0185

48. Segovia, R. A., Pennington, R. T., Baker, T. R., Souza, F. C. de, Neves, D. M., Davis, C. C., Armesto, J. J., Olivera-Filho, A. T., and Dexter, K. G. (2020). Freezing and water availability structure the evolutionary diversity of trees across the Americas.Science Advances, 6(19), eaaz5373. https://doi.org/10.1126/sciadv.aaz5373

49. Sklenář, P., Kučerová, A., Macková, J., and Romoleroux, K. (2016). Temperature Microclimates of Plants in a Tropical Alpine Environment: How Much does Growth Form Matter? Arctic, Antarctic, and Alpine Research , 48 (1), 61-78. https://doi.org/10.1657/AAAR0014-084

50. Smith, S. A., and Brown, J. W. (2018). Constructing a broadly inclusive seed plant phylogeny. American Journal of Botany,105(3), 302-314. https://doi.org/10.1002/ajb2.1019

51. Smithers, B. V., Oldfather, M. F., Koontz, M. J., Bishop, J., Bishop, C., Nachlinger, J., and Sheth, S. N. (2020). Community turnover by composition and climatic affinity across scales in an alpine system.American Journal of Botany, 107(2), 239-249. https://doi.org/10.1002/ajb2.1376

52. Stevens, P. F. (2001). Angiosperm Phylogeny Website. Version 14, July 2017 [and more or less continuously updated since].

53. ter Steege, H., Prado, P. I., Lima, R. A. F. de, Pos, E., de Souza Coelho, L., de Andrade Lima Filho, D., Salomão, R. P., Amaral, I. L., de Almeida Matos, F. D., Castilho, C. V., Phillips, O. L., Guevara, J. E., de Jesus Veiga Carim, M., Cárdenas López, D., Magnusson, W. E., Wittmann, F., Martins, M. P., Sabatier, D., Irume, M. V., .. Pickavance, G. (2020). Biased-corrected richness estimates for the Amazonian tree flora. Scientific Reports, 10(1), 10130. https://doi.org/10.1038/s41598-020-66686-3

54. Ulloa Ulloa, C., Acevedo-Rodríguez, P., Beck, S., Belgrano, M. J., Bernal, R., Berry, P. E., Brako, L., Celis, M., Davidse, G., Forzza, R. C., Gradstein, S. R., Hokche, O., León, B., León-Yánez, S., Magill, R. E., Neill, D. A., Nee, M., Raven, P. H., Stimmel, H., .. Jørgensen, P. M. (2017). An integrated assessment of the vascular plant species of the Americas. Science, 358(6370), 1614-1617. https://doi.org/10.1126/science.aao0398

55. Webb, C. O., Ackerly, D. D., McPeek, M. A., and Donoghue, M. J. (2002). Phylogenies and Community Ecology. Annual Review of Ecology and Systematics , 33 (1), 475-505. htt- 
ps://doi.org/10.1146/annurev.ecolsys.33.010802.150448

56. Wen, J., Zhang, J., Nie, Z.-L., Zhong, Y., and Sun, H. (2014). Evolutionary diversifications of plants on the Qinghai-Tibetan Plateau. Frontiers in Genetics, 5. https://doi.org/10.3389/fgene.2014.00004

57. Whittaker, R. H. (1970). Communities and ecosystems. Macmillan. https://www.cabdirect.org/cabdirect/abstract/19740615709

58. Xing, Y., and Ree, R. H. (2017). Uplift-driven diversification in the Hengduan Mountains, a temperate biodiversity hotspot.Proceedings of the National Academy of Sciences,114(17), E3444-E3451. https://doi.org/10.1073/pnas.1616063114

59. Zanne, A. E., Tank, D. C., Cornwell, W. K., Eastman, J. M., Smith, S. A., FitzJohn, R. G., McGlinn, D. J., O’Meara, B. C., Moles, A. T., Reich, P. B., Royer, D. L., Soltis, D. E., Stevens, P. F., Westoby, M., Wright, I. J., Aarssen, L., Bertin, R. I., Calaminus, A., Govaerts, R., .. Beaulieu, J. M. (2014). Three keys to the radiation of angiosperms into freezing environments. Nature,506 (7486), 89-92. https://doi.org/10.1038/nature12872.

\section{DATA AVAILABILITY STATEMENT}

The following data associated with this study have been deposited with Dryad (https://doi.org/10.5061/dryad.9cnp5hqgx): (1) species distributions models used for this study; (2) links to aggregated occurrence records from GBIF and iDigBio; (3) scripts used to analyze species distribution models and calculate climatic niches; and (4) CSV files of climatic niches, montane species lists, and genera-level summaries. Front-end access to the BiotaPhy platform can be found at www.biotaphy.github.io.

FIGURES, TABLES, and FIGURE LEGENDS 

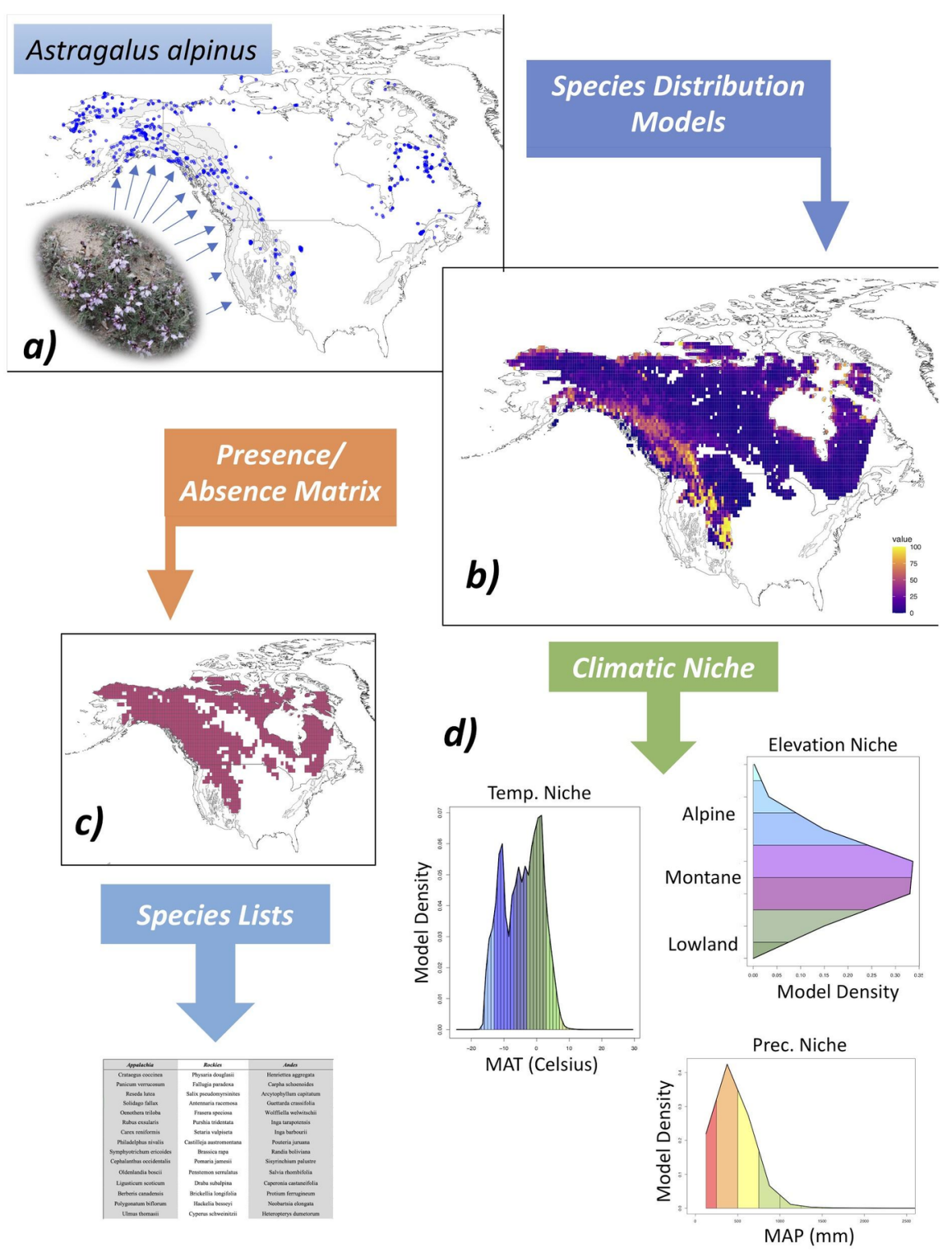

Figure 1. Conceptual illustration of project workflow and niche characterization, using Astragalus alpinus L. ('alpine milkvetch'; photo in $(a)$ ) as an example. (a) We aggregated georeferenced specimen records from GBIF and iDigBio. Here, GBIF records for A. alpinus are shown in blue. North American mountain ranges are highlighted in grey. These records were then integrated with climate data from WorldClim to build species distribution models (SDMs) using MaxEnt; $(b$ ) SDMs provided a probabilistic view of where we expected species to occur based on their known distributions. In this example, warmer (cooler) colors represent higher (lower) probability of $A$. alpinus occurring at that site (this species primarily occurs in and around higher elevation habitat in the Northern Hemisphere). The SDMs were then parsed and analyzed in two different ways, as follows: $(c$ ) We assigned each species a presence/absence rating to each site based on its SDM (requiring at least $5 \%$ across at least $25 \%$ of the area covered by that site). These presence/ absence matrices allowed us to estimate expected species richness of species in our dataset across different mountain ranges (Fig. 2). ( $d$ ) Separately from $(c)$, we also parsed each SDM by three abiotic variables - temperature, precipitation, and elevation - to build a quantitative, continuously-valued 
description of each species' occupied niche space. In this case, the SDM of A. alpinus describes a range centered within montane habitat bounded between -17 and +10 degrees $\mathrm{C}^{\circ}$ and generally below $1000 \mathrm{~mm}$ of precipitation. For temperature and precipitation, the horizontal axes in each plot indicate values for the climatic variable and the vertical axis indicates the fraction of the SDM attributable to those values. For elevation, axis orientation is switched; vertical axis represents elevational categories (alpine areas in blues, montane in purples, and foothills or lowland in greens) while the horizontal axis indicates the SDM fraction falling into each category. Thus, the climatic niche of each species was described by three vectors, which jointly describe the weighted proportion of each species range falling within different abiotic conditions.
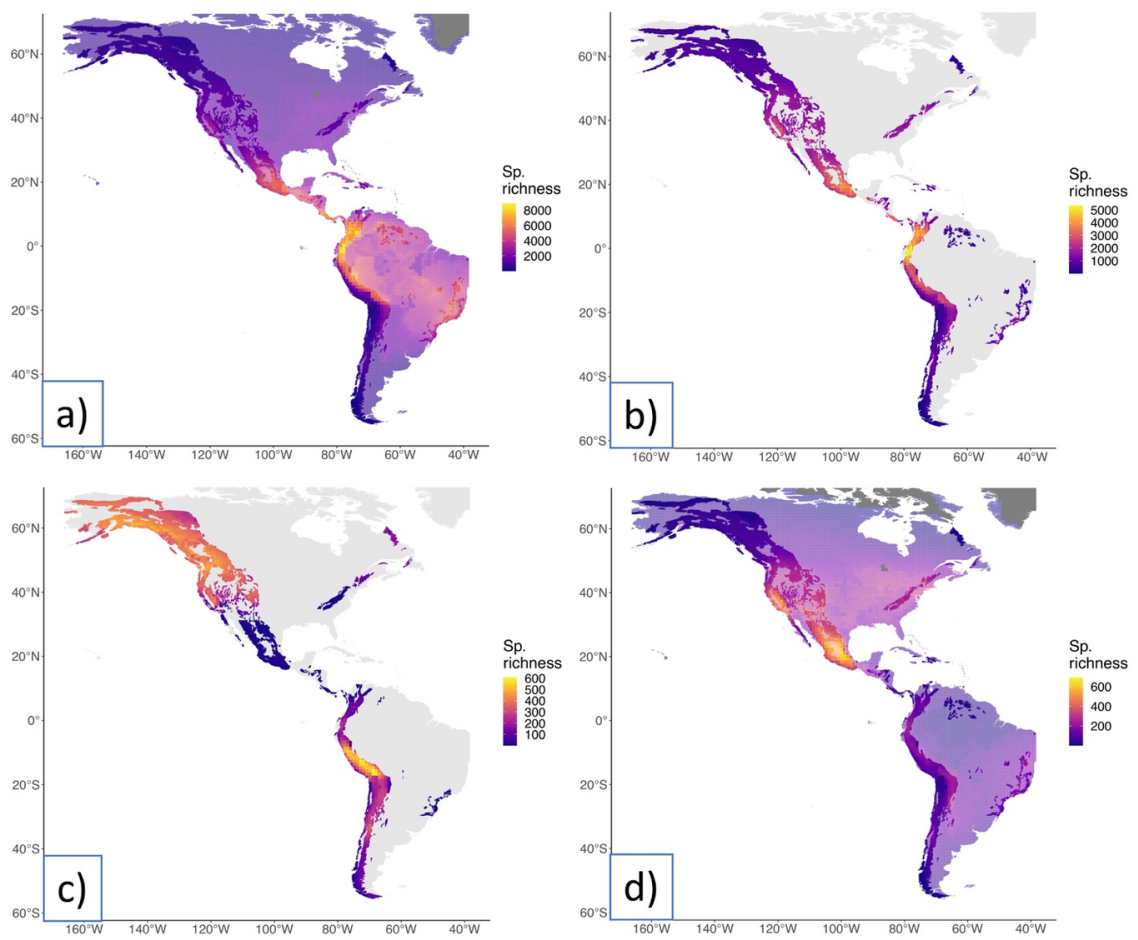

Figure 2 . Species richness across the Americas for $(a)$ all seed plants; $(b)$ only montane species; $(c)$ only alpine species; $(d)$ non-alpine species whose ranges overlapped with the same temperature and precipitation conditions as alpine species. Overall, seed plant diversity (including solely lowland species) and montane-only communities followed traditional latitudinal richness gradients, peaking near the equator. Alpine communities (panel c ), however, had their greatest diversity in the western North American cordillera and the central Andes. $(d)$ Non-alpine species whose ranges were otherwise climatically similar to alpine species showed the greatest concentration in Mexico and the southern United States (see Discussion). (Warmer [cooler] colors indicate greater [lower] species richness. Foreground: Mountain areas defined by the Global Mountain Biodiversity Assessment [GMBA; see Methods].Background: non-mountainous areas in the sampling region. Grey cells: missing or insufficient data. ) 

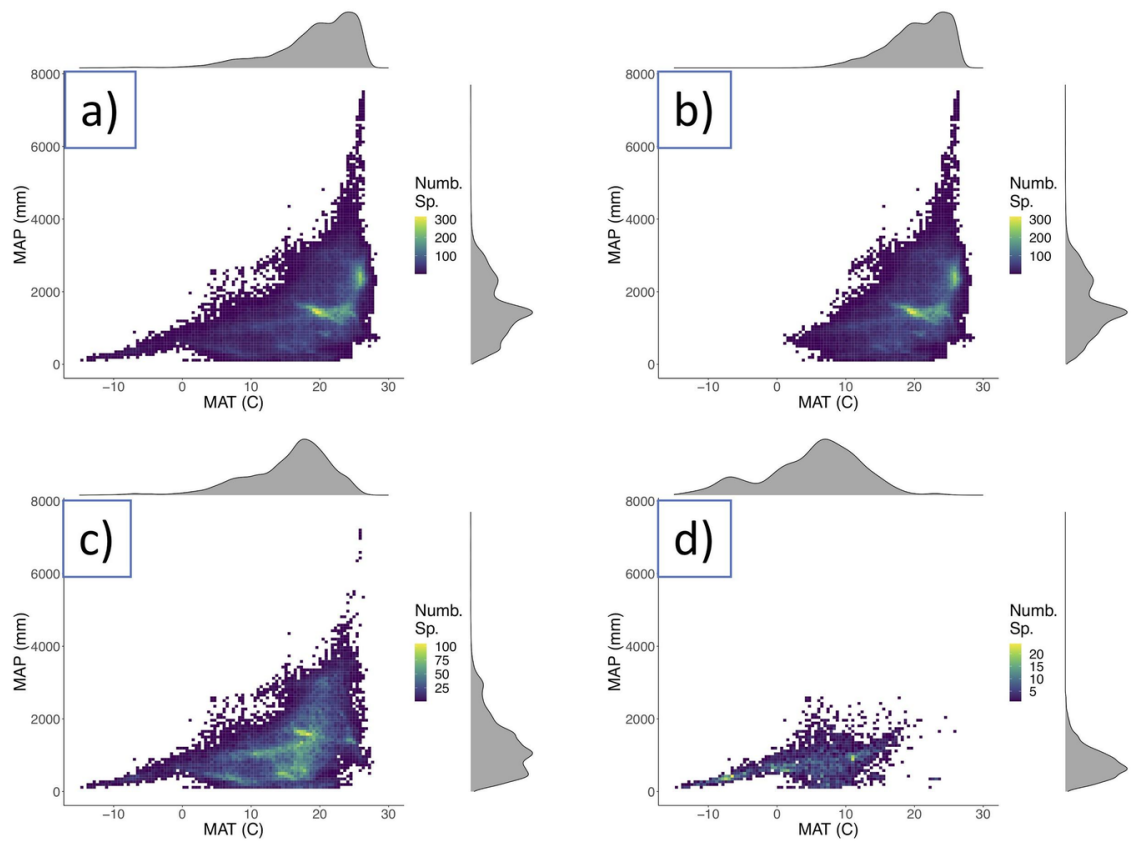

Figure 3 . Density histograms of the temperature (MAT) and precipitation (MAP) niche space occupied at the center of species' ranges for $(a)$ all seed plants in our dataset; $(b)$ only lowland species; $(c)$ only montane species; $(d)$ only alpine species. Warmer (cooler) colors indicate greater (fewer) species with that combination of niche parameters. Univariate histograms for each climate variable are given along plot margins.
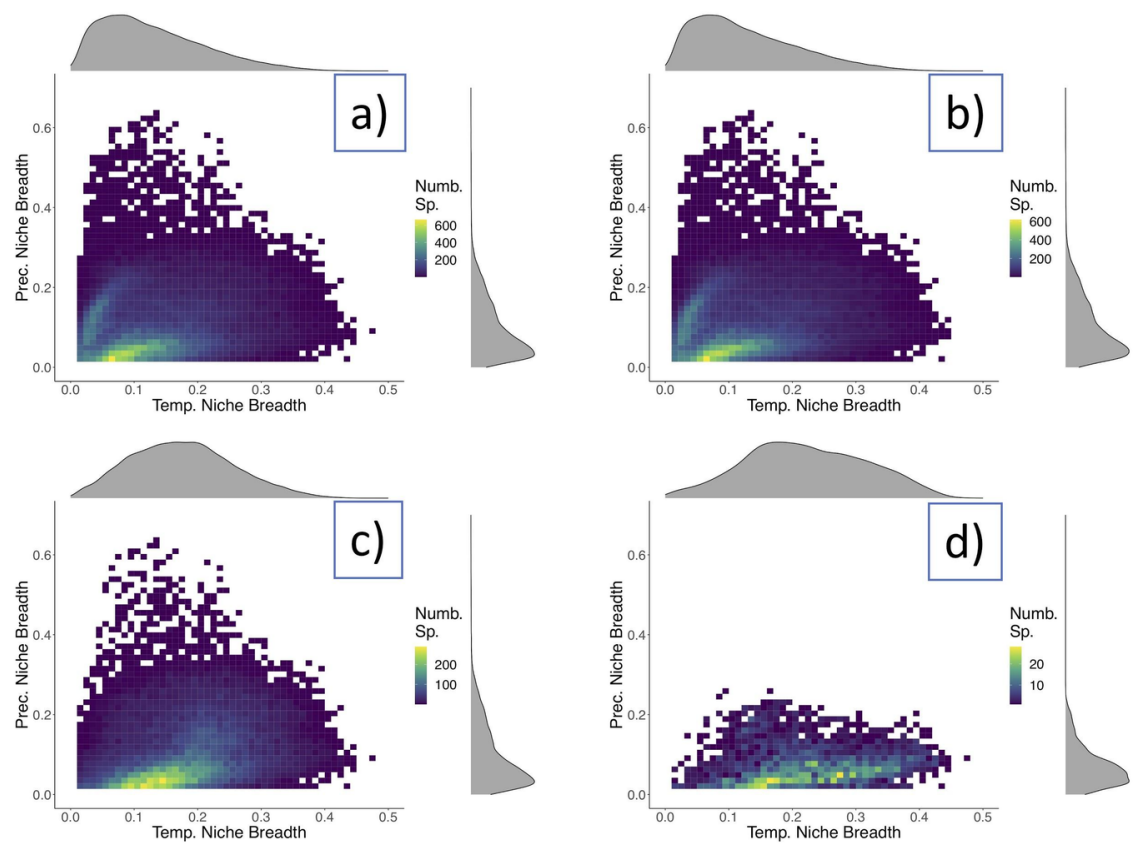

Figure 4. Density histograms of species' standardized niche breadth for temperature and precipitation among $(a)$ all seed plants in our dataset; $(b)$ only lowland species; $(c)$ only montane species; $(d)$ 
only alpine species. Warmer (cooler) colors indicate greater (fewer) species with that combination of niche parameters. Univariate histograms for niche breadth variables are given along the margins of each plot.
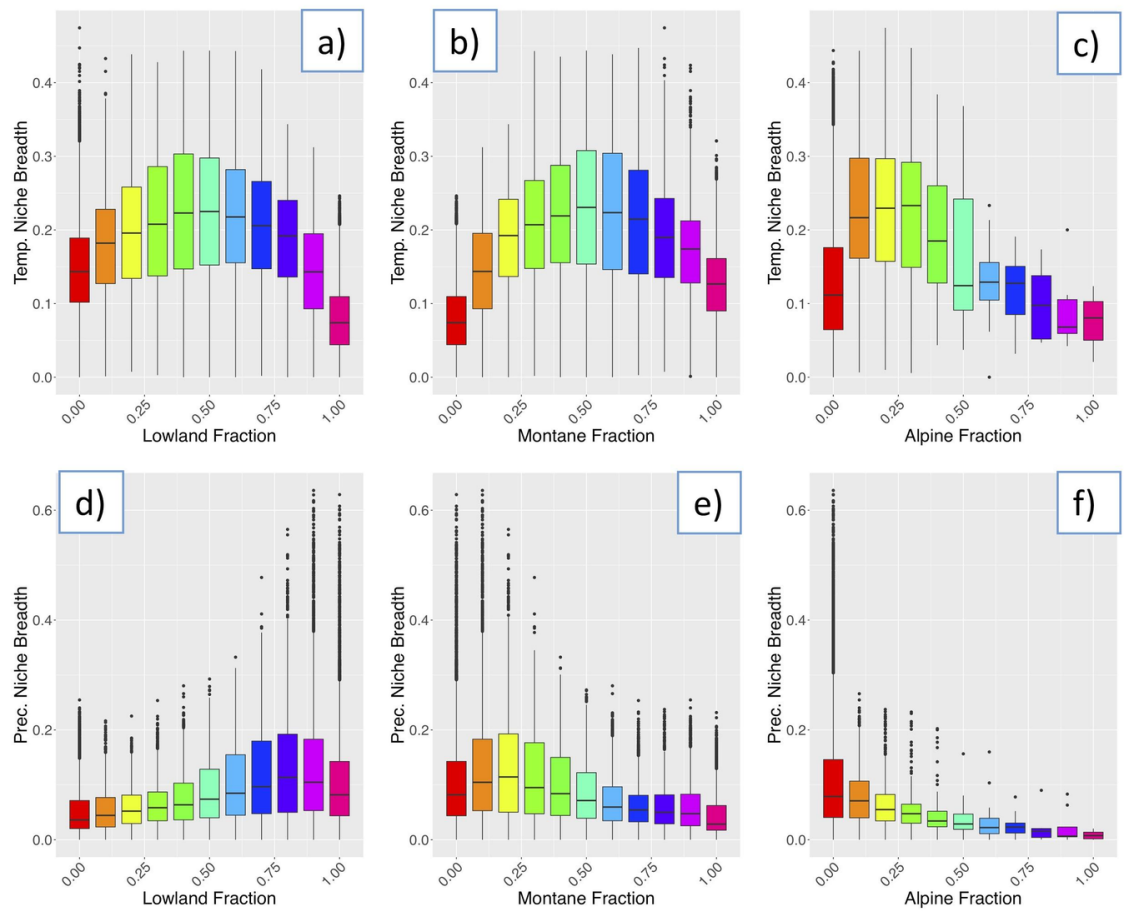

Figure 5. Temperature (top row) and precipitation (bottom row) niche breadth among species with varying proportions of their modelled range attributable to either lowland (left column), montane (middle column ), or alpine (right column ) habitat. Temperature niche breadth was maximal for generalists in any given category, whereas precipitation niche breadth was consistently narrow. 

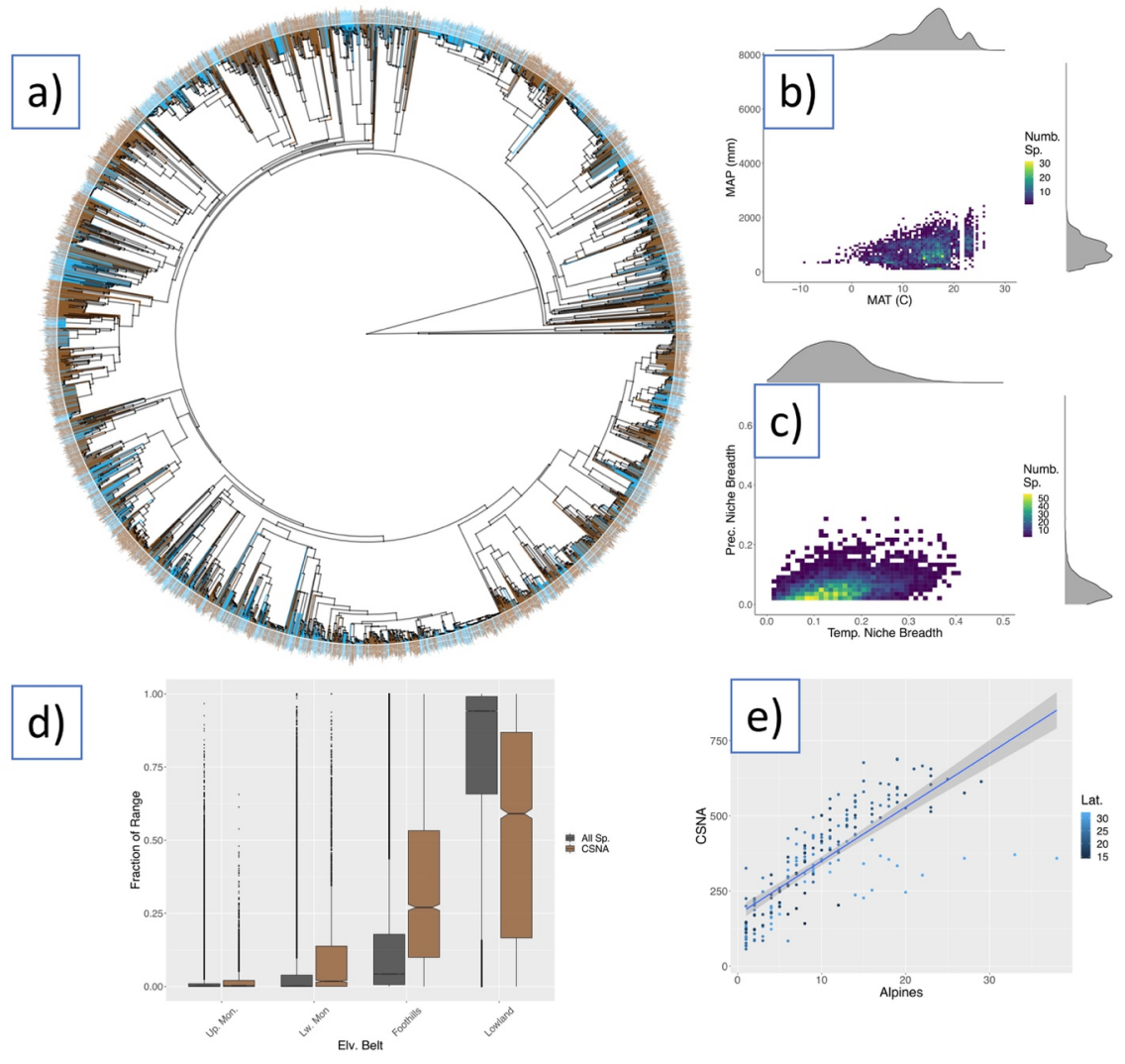

Figure 6 . Summary of climatic niches and elevational distributions of Climatically-Similar Non-Alpine (CSNA) species, defined here as non-alpine species whose ranges encompassed the same temperature and precipitation conditions as alpine taxa. (a) Phylogeny of alpine (blue tips) and CSNA (brown tips) species. At this broad scale, no clear phylogenetic separation of the two groups exists, and both groups are distributed broadly across the seed plant phylogeny. However, at the genus level, substantial taxonomic differences were observed, and these differences persisted at both the familial and ordinal levels (see Table 1 and main text). (b-c ) Density histograms of the occupied climatic niche space and niche breadth, respectively, of CSNA species, showing good overlap between their climatic conditions and those of true alpine species (compare with panels $d$ in Fig. 2-3). ( $d$ ) Elevational distribution of CSNA (brown bars ), compared to the elevational distribution of all species in our dataset ("All Sp.", grey bars ). Compared with the American seed plant species pool overall, CSNA species tended to have ranges that included a higher proportion of mountain foothills (with frost exposure) and, to a lesser extent, lower montane, habitat. Additionally, a lower proportion of their ranges were found in exclusively frost-free or lowland areas. (Up. Mon: upper montane; Lw. Mon.: lower montane; alpine elevational categories omitted here for clarity. ) (e ) Scatterplot showing a strong $\left(\mathrm{R}^{2}=0.68\right)$ and significant $(\mathrm{p}<0.001)$ positive correlation between species richness at Mexican sites where alpine richness was lowest and CSNA richness was highest, indicating that sites which support higher richness for one group likely do so for the other group was well.

Table 1. Comparison of taxonomic orders among alpines ${ }^{1}, \mathrm{CSNA}^{2}$, and non-alpine ${ }^{3}$ groups.

\begin{tabular}{l}
\hline Alpines \\
Poales \\
Asterales \\
Lamiales \\
Caryophyllales
\end{tabular}




\section{Brassicales}

Fabales

Ericales

Rosales

Saxifragales

Apiales

${ }^{1}$ Alpines clades here are the top 10 (in order) contributing most to alpine diversity in this study; ${ }^{2} \mathrm{CSNA}$ are orders contain 